\title{
Estimating the distribution characters of Larix kaempferi in response to climate change
}

\author{
Chunyan $\mathrm{Wu}^{(1-2)}$, \\ Jiapeng Shen ${ }^{(1-2)}$, \\ Dongsheng Chen ${ }^{(1-2)}$, \\ Chaoqun $\mathrm{Du}^{(3)}$, \\ Xiaomei Sun ${ }^{(1-2)}$, \\ Shougong Zhang ${ }^{(1-2)}$
}

\begin{abstract}
A better understanding of the distribution of suitable habitats of Larix kaempferi and its environmental constraints is crucial to know how global climate change will affect its growth and future dynamics. We simulated global suitable distribution areas of $L$. kaempferi under current and future climates, using different representative concentration pathway (RCP) scenarios, to evaluate the main factors affecting its geographical distribution. The results showed that under current climate conditions the suitable distribution areas of $L$. kaempferi are concentrated in Europe and Asia, followed by North America. The "Germany-Sweden-Britain" (19.42\% of the total worldwide area) and "China-Japan-North Korea" (43.11\%) regions are the cores for L. kaempferi distribution. The suitable distribution area for L. kaempferi is large in China (33.75\% of the total area). The suitable distribution areas in Asia, Europe, and China decreased and shifted northward in the RCP scenarios. The main climatic factors affecting the distribution of $L$. kaempferi were the annual mean temperature, mean temperature of the coldest quarter, annual mean precipitation, and precipitation in the driest month. L. kaempferi could adapt or move to higher latitudes/altitudes to cope with climate change. Our results contribute to the introduction, cultivation, and management of L. kaempferi and potentially of other deciduous gymnosperms.
\end{abstract}

Keywords: Suitable Distribution Areas, Maxent Model, Environmental Variable, RCPs, Cultivation and Management

agriculture (Dyderski et al. 2018). Changes in species distribution are becoming more and more common, in particular latitudinal and altitudinal changes in the northern regions (Nakada \& Fukatsu 2012).

Predicting changes in the potential distribution areas of species under global climate change has become a topic of interest in current research (Rehfeldt \& Jaquish 2010, Dyderski et al. 2018), and is essential both to assess the impacts of climate change on forests and develop adaptive forest management strategies (Zhang et al. 2015, 2020, Wang et al. 2016).

Previous studies have demonstrated that temperature and precipitation influence plant physiology (Obojes et al. 2018), thereby affecting ecological processes (Rehfeldt \& Jaquish 2010) and ultimately leading to changes in the geographical distribution of plant species worldwide (Dyderski et al. 2018, Mamet et al. 2019). For example, the plant metabolic rate is directly influenced by increasing temperatures, resulting in major changes in their growth, development, reproduction and geographic distribution (Lu et al. 2015). Differences in precipitation regimes are reflected in the distribution of plant species along polar or altitudinal isopleths (Romo et al. 2013). In addition, the interaction between vegetation and climate must be taken into account to understand the adaptability and response of vegetation to climatic factors (Nakada \& Fukatsu 2012).
Determining the distribution of species and their potential establishment in climate-friendly habitats is basic for many ecosystem management activities (Zhang et al. 2015, Wang et al. 2016). Recently, species distribution models (SDMs) have been used to understand the impacts of global climate change on the potential distribution areas of various species (Romo et al. 2013, Zhang et al. 2015) as well as for biodiversity conservation purposes (Mateo et al. 2011, Lu et al. 2015). The commonly used SDMs include generalized linear models, classification regression trees, generalized additive models (GAMs - Hastie \& Tibshirani 1990), genetic algorithm-based rule combination prediction models (GARPs), niche models (Bioclim), and maximum entropy models (Maxent - Padalia et al. 2014). These models are different and cannot be used for most tree species, as the location of study areas, research scales, environmental variables and spatial resolutions, different ecological characteristics of the species, and the sample size can affect the results. However, in the last deceade the Maxent model has been widely used in the study of the potential distribution areas of suitable habitats of species ( $\mathrm{Li}$ et al. 2013). This model is particularly suitable for predicting the geographical distribution of species with small sample sizes or partial sample data (Padalia et al. 2014).

Larix kaempferi (Lamb.) Carr is an important woody species in fast-growing planta- 
Tab. 1 - Main statistics of site and environmental factors at the 108 plots analyzed.

\begin{tabular}{lcccccc}
\hline \multirow{2}{*}{ Factor } & \multicolumn{2}{c}{$\begin{array}{c}\text { Warm temperate } \\
\text { zone }\end{array}$} & \multicolumn{2}{c}{$\begin{array}{c}\text { Northern subtropic } \\
\text { zone }\end{array}$} & \multicolumn{2}{c}{$\begin{array}{c}\text { Mid-temperate } \\
\text { zone }\end{array}$} \\
\cline { 2 - 7 } & Mean & SE & Mean & SE & Mean & SE \\
\hline Age & 17.64 & 1.76 & 21.66 & 1.06 & 23.67 & 2.21 \\
\hline DBH & 11.52 & 1.15 & 18.98 & 0.94 & 16.62 & 1.07 \\
\hline Density & 1912 & 182 & 740 & 82 & 1154 & 105 \\
\hline Longitude & 106.01 & 0.04 & 109.89 & 0.03 & 124.92 & 0.03 \\
\hline Latitude & 34.24 & 0.02 & 30.77 & 0.01 & 42.47 & 0.01 \\
\hline Altitude & 1647 & 17 & 1747 & 8 & 380 & 10 \\
\hline
\end{tabular}

tion in China, and it is also the main forest tree species of alpine coniferous forests in northeastern China, Inner Mongolia forest area, and north and southwest China (Cáceres et al. 2017). Larix kaempferi has a straight trunk, high growth rate, and good wood quality (Shao 1985, Nakada \& Fukatsu 2012). It is endemic to Japan, and native to the central mountainous region of the Honshu Island (Pâque 2002). The boundaries of L. kaempferi distribution are Mt. Zao in Miyagi Prefecture in the north and east, Mt. Hakusan in the west, and Mt. Tengu and Mt. Yamazumi of the Akashi Mountain Range in the south, and the eight representative provenances are Kawakami-Higashiyamanashi, Yatsugatake, Asama, Fuji, Minami-Alps (The South Japan Alps), Nikko, Kita-Alps (The North Japan Alps), and Kiso. L. kaempferi grows well in these areas, and artificial selection, hybridization, and development of new varieties are being conducted (Hoshi 2004). L. kaempferi was introduced and cultivated in Europe, North America, and Asia, in the early $19^{\text {th }}$ century (Shao 1985, Ma 1992, Pâque 2002).

The successful introduction and cultivation of plant species depends on the availability of environmental conditions suitable for its growth (Huang et al. 1996). In recent years, studies on L. kaempferi forests have been conducted on the physical and chemical properties of soil (Kotani et al. 2019), the growth processes and structural fea- tures of stands in different areas (Yoshida et al. 2005, Fukatsu \& Nakada 2018), the characteristics of the understory plant diversity (Li et al. 2016), and the productivity and ecological adaptability (Chen et al. 2015). However, the effects of climate change on the distribution of L. kaempferi have not been documented. Therefore, it is necessary to explore the future potential distribution areas of L. kaempferi under different climate change scenarios.

The present study combined GIS with the Maxent model to assess the characteristics of suitable distribution areas for L. kaempferi under a changing climate. Our objectives were to: (i) simulate the suitable distribution area of L. kaempferi in the current and future climate scenarios with different representative concentration pathways (RCPs); and (ii) determine the main climatic factors affecting the distribution pattern of L. kaempferi with different altitude gradients. The results of this study are expected to provide significant theoretical background to guide the cultivation and effective management of $L$. kaempferi.

\section{Materials and methods}

\section{Distribution data of L. kaempferi}

L. kaempferi is a full-sun tree, with strong adaptability to climate, growing in regions of $35^{\circ} 20^{\prime}-38^{\circ} 10^{\prime} \mathrm{N}, 136^{\circ} 45^{\prime}-140^{\circ} 30^{\prime} \mathrm{E}$, with altitude 1200-2500 m a.s.l. (Cáceres et al. 2017), where the annual average tempera- ture is $2.5-12.0^{\circ} \mathrm{C}$ and annual precipitation is 500-1400 mm (Cáceres et al. 2017). The growth rate is higher in sites with high air humidity and high precipitation (Huang et al. 1996). It has limited cold tolerance, and is sensitive to soil fertility and moisture (Shao 1985). The current global distribution data of $L$. kaempferi was obtained from the Global Biodiversity Information Database (GBIF - http://www.gbif.org/), the National Herbarium of America (http://www.nmnh. si.edu/botany), and the Chinese Herbarium (CVH - http://www.cvh.ac.cn/) specimen information platforms.

Some 108 L. kaempferi plots $(40 \times 25 \mathrm{~m}$, $0.1 \mathrm{ha}$ ) were established in three typical cultivation areas for the species (Nagaike et al. 2003, Chen et al. 2016): (i) the north subtropical sub-high mountain area (Changlinggang Forest Farm, Hubei); (ii) the warm temperate middle mountain area (Xiaolongshan Forest Farm, Gansu); (iii) the mid-temperate low mountain area (Liaoning Dagujia Forest Farm). Plots were grouped in 3 age classes: (I) young forests (<20 years); (ii) middle-aged forest (20-30 years); (iii) pre-mature forest (30-40 years). In each plot, the diameter at the breast height (DBH), tree height, first living branch height, crown width (four sides) were measured for all trees. Morever, coordinate information (latitude, longitude and altitude) of each tree was collected (Tab. 1).

A specific literature search was also carried out on current $L$. kaempferi worldwide distribution (Mamet et al. 2019). We investigated the peer-reviewed literature on $L$. kaempferi under rapid climate changes, finding a total of 83 publications, including 181 scope-limited observations of the dynamic changes of larch. We obtained records from a total of 253 sites worldwide, including both natural and introduced $L$. kaempferi distributions (Fig. 1). To determine the potential scope adjustment factors beyond climate change, we also retrieved from each study the following information: start year, end year, total study area, number of tree species, and number of studies on L. kaempferi in each country.

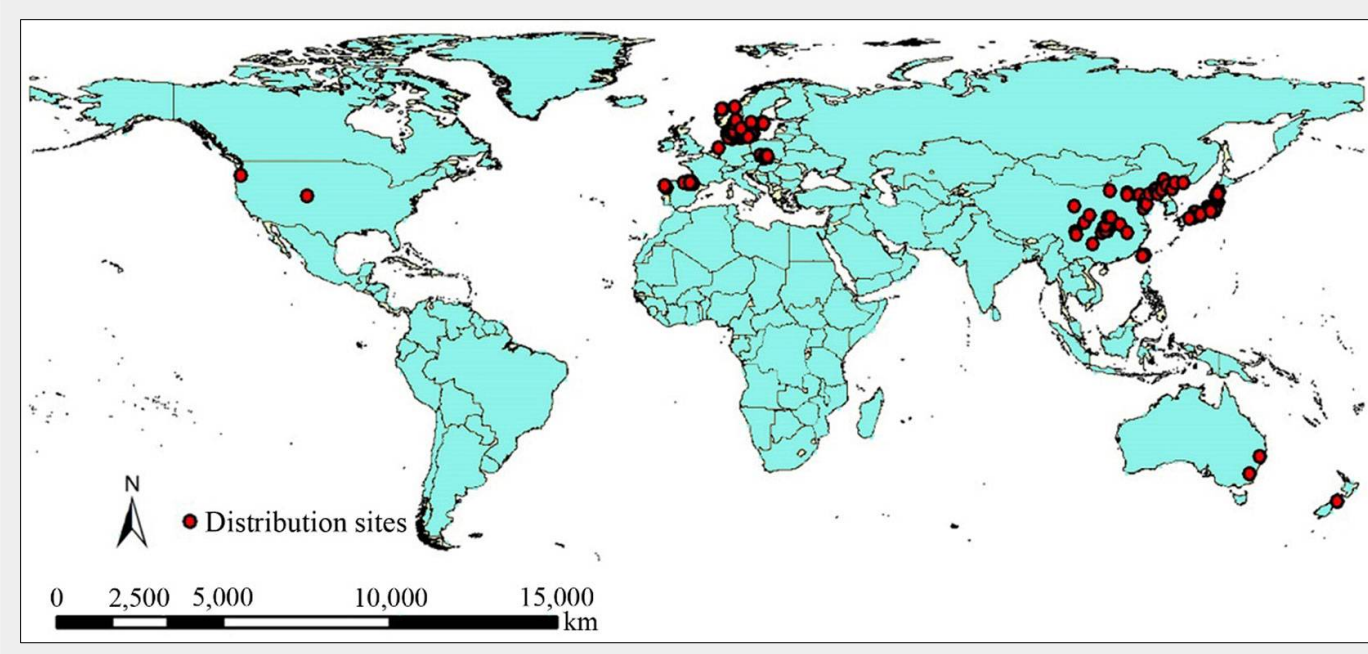

Fig. 1 - The temporal global distribution sites of Larix kaempferi. 


\section{Data analyses}

To reflect the climate data of the current period, we obtained data regarding 19 climate variable from the WorldClim database (http://worldclim.org), with a spatial resolution of $2.5^{\prime}$, over the period 19502000. Moreover, we generated climate data using the IDW (inverse distance weight) spatial interpolation method in GIS, including observation data from meteorological stations around the world (Hijmans et al. 2005). Climate data for the year 2070 was generated using the CCSM4 climate system model (Wu et al. 2017), with greenhouse gas emission scenarios for four typical concentration targets: RCP2.6, RCP4.5, RCP6.0, and RCP8.5. These scenarios represented an increase of 2.6, 4.5, 6.0, and $8.5 \mathrm{~W} \mathrm{~m}^{-2}$, respectively, of the radiative force in the year 2100. RCP2.6 is a warming mitigation scenario, RCP4.5 and RCP6.0 are stable scenarios, while RCP8.0 is a high greenhouse gas emission scenario, which correspond to an increase in the mean global temperature of 1.6, 2.4, 2.8, and 4.3 ${ }^{\circ} \mathrm{C}$, respectively (Stocker et al. 2013, Wu et al. 2017). The environmental variable data was processed using the software ArcGIS $^{\circledR}$ ver. 10.2 (ESRI, Redlands, CA, USA), and the layer data of each environment was obtained for model prediction. The mapping data was sourced from the DIVA-GIS website (http://www. diva-gis.org/) and the National Basic Geographic Information System (http://nfgis. nsdi.gov.cn/).

The software Maxent v. 3.3.3 (https://bio diversityinformatics.amnh.org/open_sourc e/maxent/ - Phillips et al. 2006) was used to identify the potential distribution areas of L. kaempferi. To this purpose, $70 \%$ of the available data was randomly selected for model training, $15 \%$ was used for model verification, and $15 \%$ was used for model fitting. Model accuracy was evaluated using the receiver operating characteristic (ROC) curve, which was plotted with specificity (1specificity) and sensitivity (1-omission rate). The AUC value (the area enclosed by the ROC curve) does not depend on the threshold. The magnitude of the AUC value reflects the predictive ability of the model (Chen et al. 2012). The larger the AUC value, the better the accuracy of model predictions. When $0.7<A \cup C<0.8$ was classified as useful predictive, $0.8<A U C<0.9$ as good predictive, and AUC >0.9 as highly predictive (Swets 1988, Wiley et al. 2003). The Jackknife method was used to test and evaluate the effects of various environmental factors on the potential distribution areas of $L$. kaempferi. The distribution threshold was calculated by randomly selecting $10 \%$ of the data in the training set. The output distribution value was a logistic, and the output was in ASCII format. The maximum number of iterations was set to 5,000 , and the random operation was set to 15 times. The final average was used to evaluate the effect of the model. The calculated result showed that the distribution threshold of the model was 0.3092 , i.e., the presence of L. kaempferi in areas showing values of 0.3092 or less is a small probability event. Therefore, these areas were regarded as unsuitable for L. kaempferi cultivation and discarded. A distribution threshold of $0.3092-0.5083$ indicated a suitable distribution area (SA), while values in the range $0.5083-0.9624$ indicated the most suitable distribution area (MSA). The final prediction results were then imported into ArcGIS $^{\circledast}$ v. 10.2 software to prepare maps using the "Reclass" tool, and the surface area of the different suitable regions was calculated using the "Raster Reclassify" tool.

We employed the contribution rate of environmental variables, the displacement value, and the Jackknife method to assess the importance of environmental variables in delineating the geographic patterns of potential distribution areas for $L$. kaempferi (Li et al. 2016). The contribution rate increased the gain value by gradually correcting the coefficient of a single essential factor, and the gain value was assigned to the environment variable that determined this essential factor. The replacement value was obtained by randomly replacing the value of the environmental variable in the training point set, and determining the reduction in the degree of the training AUC value. Jackknife created a new model by sequentially using or excluding a variable, and the difference in regularized training gain, test gain, and AUC value of the model was used for evaluating model performance.

The probability distribution obtained with the largest entropy is considered as the optimal distribution by Maxent model, using non-random relationships between environmental factors, such as climate, altitude, and vegetation types, at species distribution sites or research areas under constraints. This can predict the suitable distribution areas of a species, and construct a spatial distribution model at the geographic scale. Model prediction results, in combi- nation with GIS, can be used to obtain an intuitive map of the suitable distribution areas for the species.

\section{Results}

\section{Spatial differentiation of L. kaempferi} under temporal climate conditions

The result of model fitting showed a high accuracy of the model predictions using Maxent (Fig. 2).

The result showed that the establishment of L. kaempferi is increasing (i.e., advance or infilling) in $56 \%$ of the research sites, in $14 \%$ is decreasing (i.e., recession or thinning), while no change was detected for $30 \%$ of the analyzed sites.

The suitable (SA) and most suitable (MSA) distribution areas for L. kaempferi occupied a global area of $334.18 \times 10^{4} \mathrm{~km}^{2}$ and $58.35 \times 10^{4} \mathrm{~km}^{2}$, respectively (Fig. 3). The potential distribution area in Europe was the largest, accounting for $52.00 \%$ (SA) and $40.67 \%$ (MSA) of the total area, respectively. This was followed by Asia, with the suitable and most suitable distribution areas covering $46.67 \%$ and $57.34 \%$ of the total area, respectively. However, Africa and South America did not show any potential distribution areas for L. kaempferi (Tab. 2).

The potential distribution areas for $L$. kaempferi, including both suitable and most suitable distribution areas, were mainly concentrated in Europe and Asia. In Europe, these areas principally are present in Britain, Ireland, Italy, the Netherlands, France, Poland, Sweden, and Germany, centering in the "Germany-Sweden-Britain" region, each accounting for $9.07 \%$, $5.23 \%$, and $5.12 \%$ of the total areas, respectively. In Asia, the suitable and most suitable distribution areas were mainly located in Japan, South Korea, North Korea, and China, centering in "China-Japan-North Korea" region, accounting for $33.75 \%, 6.23 \%$ and $3.13 \%$ of the total areas, respectively. In other continents, no significant suitable distribution areas were found. However,

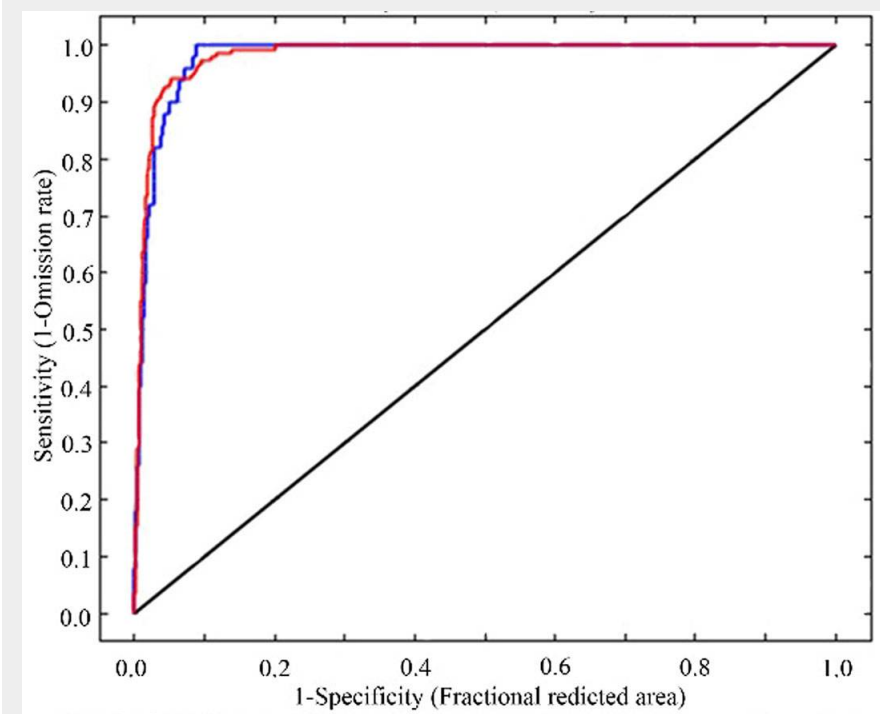

- AUC of training set " ALC of verification set - AUC of stochastic prediction
Fig. 2 - The result of receiver operating characteristic curves. 


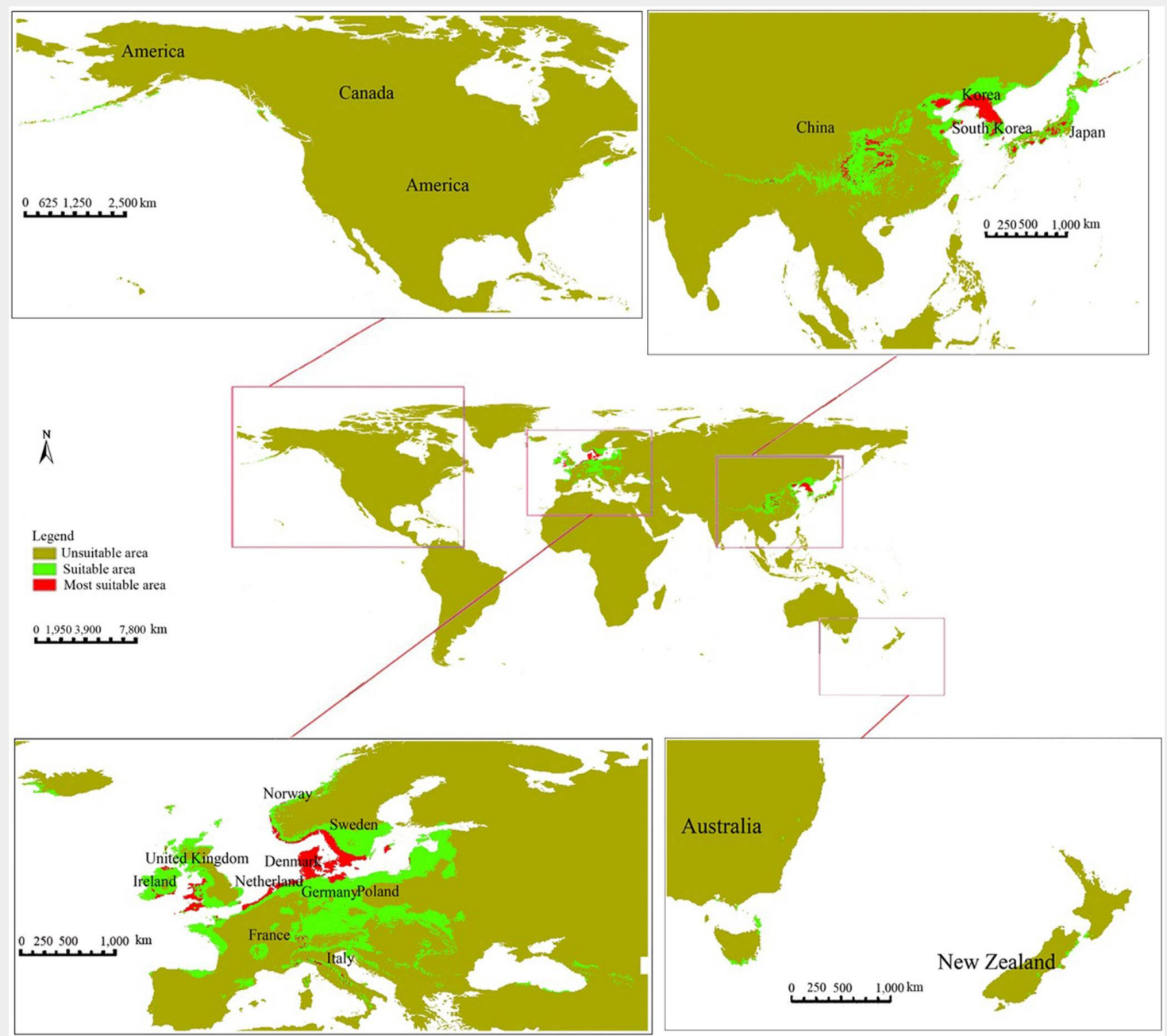

Fig. 3 - The global potential distribution area for Larix kaempferi under current climate conditions.

some regions scattered across the United (Fig. 3).

States (North America), Canada (North China presented the main distribution arAmerica), Australia (Oceania), and New eas for L. kaempferi in Asia. The suitable Zealand (Oceania) were found to be some- and most suitable distribution areas ocwhat suitable for L. kaempferi cultivation cupy $115.24 \times 10^{4} \mathrm{~km}^{2}$ and $17.29 \times 10^{4} \mathrm{~km}^{2}$, ac-

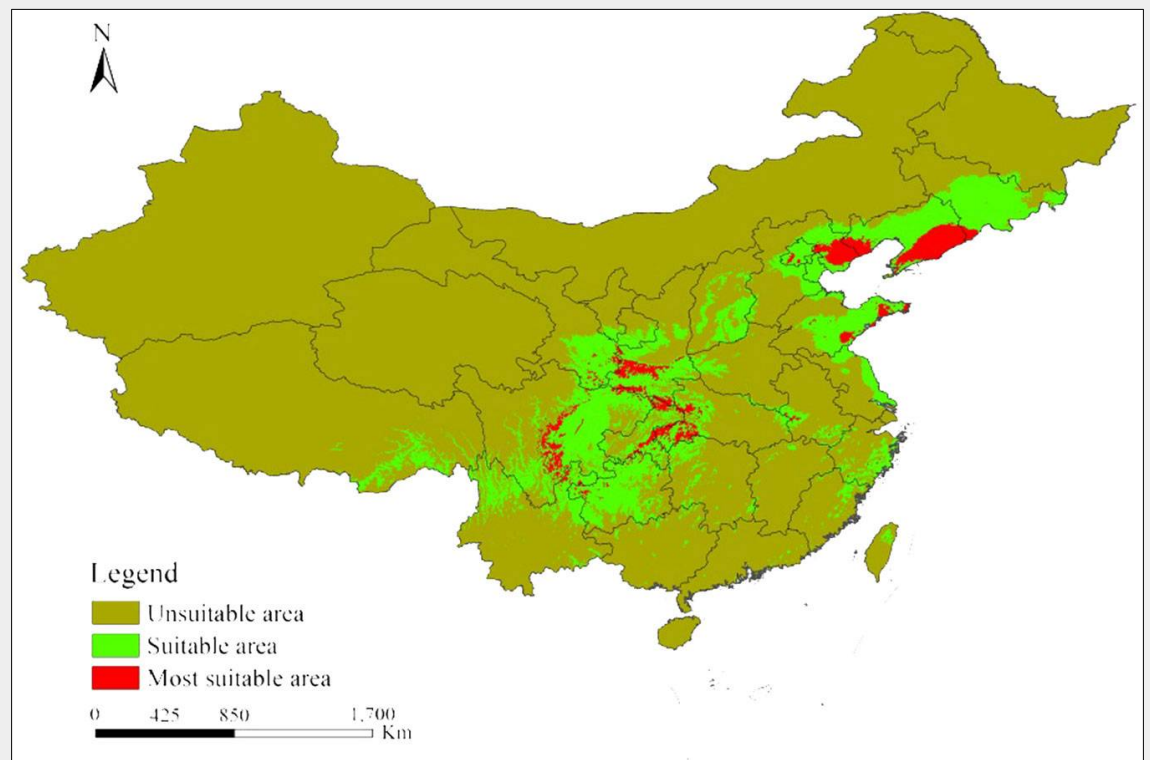

Fig. 4 - The potential distribution area for Larix kaempferi in China under current climate condition. counting for $34.48 \%$ and $29.63 \%$ of the total area, respectively. These areas were mainly located in Jilin, southeastern Liaoning, western Hubei, Hebei, central and eastern Sichuan, Chongqing, Shandong, southwestern Shaanxi, southeastern Gansu, Guizhou, and southeastern Heilongjiang. The most suitable distribution areas in Chinese region within "Dabashan-Wushan" were concentrated in Sichuan (15.24\%), Shaanxi Province (12.91\%) and Hubei (9.58\%), accounting for $37.73 \%$ of the most suitable distribution areas in China. The most suitable distribution areas within "Liaodong

Tab. 2 - The potential global suitable areas of Larix kaempferi. (SA): suitable area (distribution threshold: 0.30920.5083 ); (MSA): most suitable area (distribution threshold: $0.5083-0.9624$ ). For more details, see text.

\begin{tabular}{|c|c|c|c|}
\hline \multirow{2}{*}{ Region } & SA & MSA & Total \\
\hline & \multicolumn{3}{|c|}{$\left(\times 10^{4} \mathrm{~km}^{2}\right)$} \\
\hline Europe & 173.80 & 23.73 & 197.53 \\
\hline Asia & 155.95 & 33.46 & 189.41 \\
\hline North America & 3.33 & 1.07 & 4.60 \\
\hline Oceania & 1.10 & 0.09 & 1.19 \\
\hline Global & 334.18 & 58.35 & 392.73 \\
\hline
\end{tabular}


Peninsula-Hebei" were located mainly in Liaoning (31.94\%) and Hebei (11.92\%), representing for $43.86 \%$ of the most suitable distribution areas of China (Fig. 4).

\section{Spatial differentiation of $L$. kaempferi in} different RCP scenarios

The distribution of L. kaempferi exhibited different degrees of variations under different RCPs scenarios (Fig. 5). Compared to the current climate condition, the suitable distribution areas (SA) for L. kaempferi increased by $2.81 \%, 4.81 \%, 3.80 \%$, and $3.25 \%$ in the four RCPs scenarios, respectively. However, the most suitable distribution area (MSA) decreased by $14.85 \%, 15.10 \%$, and $6.46 \%$ in RCP2.6, RCP4.5, and RCP6.0 scenarios, respectively, while it increased by $1.40 \%$ in RCP8.5 scenario.

The suitable and most suitable distribution areas of L. kaempferi in Africa and South America also have not found under the four RCPs scenarios (Tab. 3). The potential distribution area in North America increased under the four RCPs scenarios, mainly in the coastal areas of western United States and southwestern Canada. The potential distribution areas showed an increase, particularly in RCP8.5, indicating that the range of suitable distribution area for L. kaempferi in the United States and Canada will expand in case of the four RCPs scenarios (Fig. 5, Tab. 3).

The potential distribution area of $L$. kaempferi in Asia showed a decreasing trend under the four RCPs scenarios (Tab. 3). The suitable distribution area decreased mainly in China, North Korea, and Japan, however, the most suitable distribution area increased in Russia, suggesting that the suitable distribution area of L. kaempferi in Asia would shift northward under the four RCPs scenarios (Fig. 5, Tab. 3).

Suitable distribution areas of L. kaempferi in the European region exhibited varying trends under the four RCP scenarios (Tab. 3). The potential distribution areas in Finland and Sweden, in northern Europe, exhibited a gradual increase, indicating that the suitable distribution area of L. kaempferi has a tendency to move northward in Europe (Fig. 5, Tab. 3).

The potential distribution area of $L$. kaempferi did not exhibit marked changes in Oceania under the four RCPs scenarios (Tab. 3). The distribution area increased slightly, except in the RCP8.5 scenario, and the most suitable distribution area also showed a slight increase (Fig. 5, Tab. 3).

The suitable distribution area of L. kaempferi in China decreased by $8.49 \%, 4.39 \%$, $7.81 \%$, and $8.80 \%$ in RCP2.6, RCP4.5, RCP6.0, and RCP8.5 scenarios, respectively (Fig. 6). In addition, the most suitable distribution area further decreased by $9.16 \%, 17.52 \%$, $2.95 \%$ and $1.34 \%$ in the four RPCs, respectively.

Our results indicated that the suitable and most suitable areas of $L$. kaempferi will reduce and shift northeast at varying degrees in China (Fig. 6). Nearly half of the

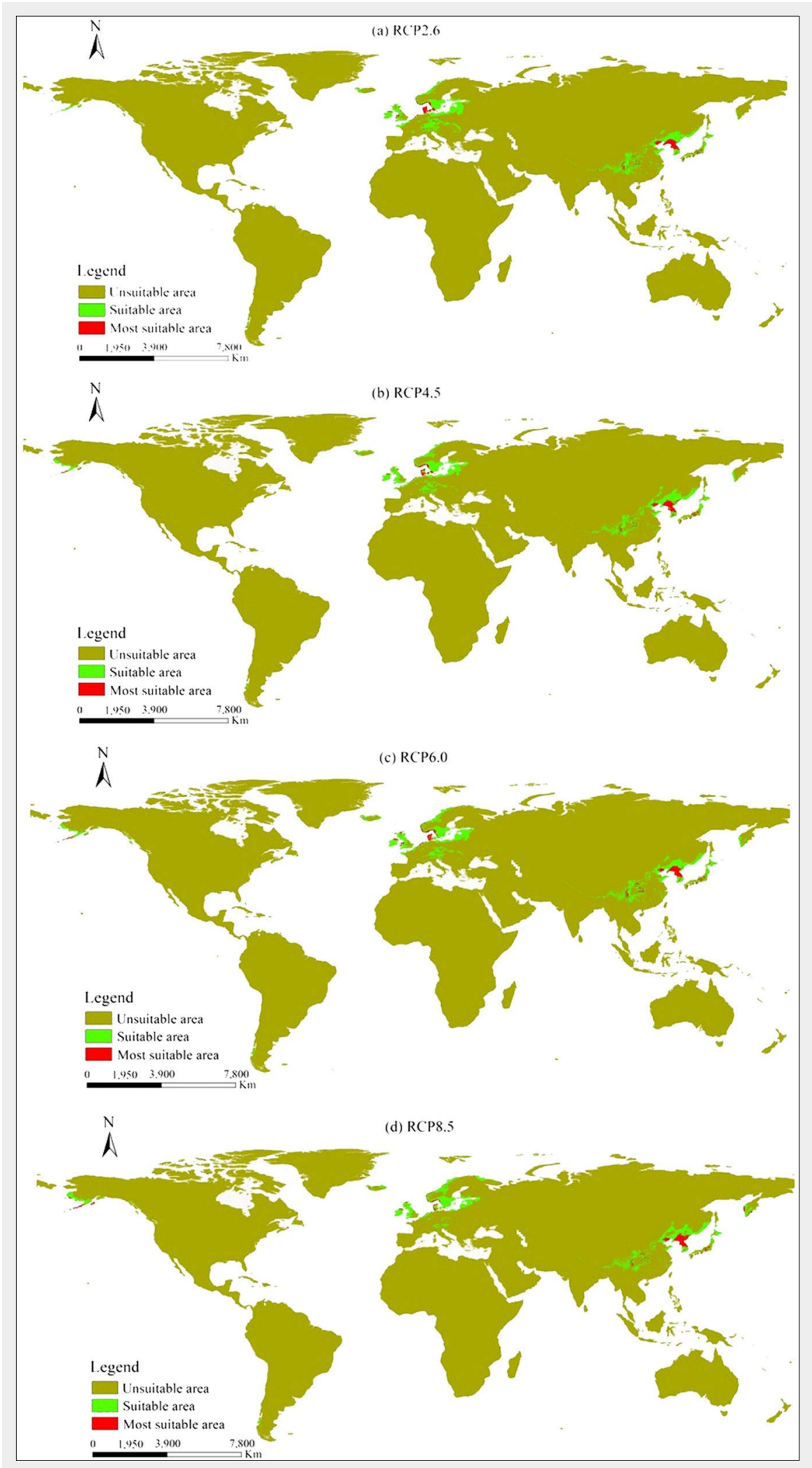

Fig. 5 - Variation of the global potential distribution area predicted for Larix kaempferi under different RCPs.

most suitable distribution areas would disappear due to climate change. For example, only $0.77 \times 10^{4} \mathrm{~km}^{2}$ persisted in the RCP8.5 scenario in Hubei province (Fig. 6). Conversely, the most suitable distribution area in Liaoning Province would increase to $6.25 \times 10^{4} \mathrm{~km}^{2}$ (Fig. 6), indicating that Liaon- ing province is the most suitable area for $L$. kaempferi under the different RCPs.

Response to environmental variables The annual average temperature (Bio-1) was the main climatic factor affecting the distribution pattern of L. kaempferi, with a 
Tab. 3 - The potential global suitable area of Larix kaempferi under different RCPs scenarios. (RCPs): representative concentration pathways; (SA): suitable area (distribution threshold: 0.3092-0.5083); (MSA): most suitable area (distribution threshold: $0.5083-$ 0.9624). For more details, see text.

\begin{tabular}{|c|c|c|c|c|c|c|c|c|c|c|c|c|}
\hline \multirow{3}{*}{$\begin{array}{l}\text { RCPs } \\
\text { scenarios }\end{array}$} & \multicolumn{12}{|c|}{ Regions $\left(\times 10^{4} \mathrm{~km}^{2}\right)$} \\
\hline & \multicolumn{2}{|l|}{ Europe } & \multicolumn{2}{|l|}{ Asia } & \multicolumn{2}{|c|}{ North America } & \multicolumn{2}{|c|}{ Oceania } & \multicolumn{2}{|c|}{ South America } & \multicolumn{2}{|c|}{ Africa } \\
\hline & SA & MSA & SA & MSA & SA & MSA & SA & MSA & SA & MSA & SA & MSA \\
\hline RCP2.6 & 185.57 & 17.68 & 145.07 & 31.27 & 11.23 & 0.84 & 1.24 & 0.09 & 0.48 & 0 & 0 & 0 \\
\hline RCP4.5 & 181.95 & 14.54 & 147.96 & 31.68 & 19.12 & 3.46 & 0.98 & 0.09 & 0.82 & 0 & 0 & 0 \\
\hline RCP6.0 & 181.76 & 16.84 & 144.07 & 33.72 & 19.09 & 3.17 & 1.34 & 0.08 & 0.89 & 0 & 0 & 0 \\
\hline RCP8.5 & 176.12 & 14.31 & 138.19 & 35.72 & 27.7 & 7.97 & 1.32 & 0.1 & 1.83 & 0.01 & 0 & 0 \\
\hline Current & 173.8 & 23.73 & 155.95 & 33.46 & 3.03 & 0 & 1.1 & 0.09 & 0.07 & 0 & 0 & 0 \\
\hline
\end{tabular}

contribution rate of $28.5 \%$ (Tab. S1 in Supplementary material). This was followed by precipitation of the driest month (Bio-14), the monthly mean temperature difference between day and night (Bio-2), and the coldest quarterly mean temperature (Bio11). The cumulative contribution rate of these six variables was $83.1 \%$, indicating that these six variables mostly contribute to the variations in distribution pattern. The environment variable with the highest permutation value was the coldest quarter average temperature (Bio-11), with a value of $56.90 \%$, followed by the average annual precipitation (Bio-12), indicating that these two variables were particularly important in the delineation of suitable distribution areas of L. kaempferi.

The results of the Jackknife test showed that when considering individually, the three variables with the highest regularization training gain and test gain were the coldest seasonal mean temperature (Bio11), the annual mean temperature (Bio-1), and the driest seasonal mean temperature (Bio-9 - see Fig. S1 in Supplementary material). The three variables with the highest AUC values were the annual average temperature (Bio-1), the coldest seasonal average temperature (Bio-11), and the coldest monthly minimum temperature (Bio-6). This suggests that these variables reflect significant information, as the regularization training gain, test gain and AUC value exhibit little change. The three variables with the most reduction were the seasonal variation coefficient of precipitation (Bio15), isotherm (Bio-3), and the hottest month maximum temperature (Bio-5), further suggesting that these variables contain more information than other variables. The main factors affecting the geographical distribution of L. kaempferi were temperature (annual average temperature, coldest seasonal average temperature) and precipitation (annual average precipitation, driest month precipitation). We found a significant difference in the trends of centroid changes for precipitation between the early and late growth periods for this species. Receding L. kaempferi occurred near the centre of the envelopes, where conditions were becoming warmer and wetter. For the North American continent, the number of studies was limited, but suggested that L. kaempferi was tracking wetter conditions, and that changes in precipitation and temperature trends were variable among these sites.

\section{Discussion}

Since the 1980s, the overall distribution range of L. keampferi has changed as a consequence of climate warming, though with a varying degree in Europe and Asia. This may be attributed to the difference in cli-

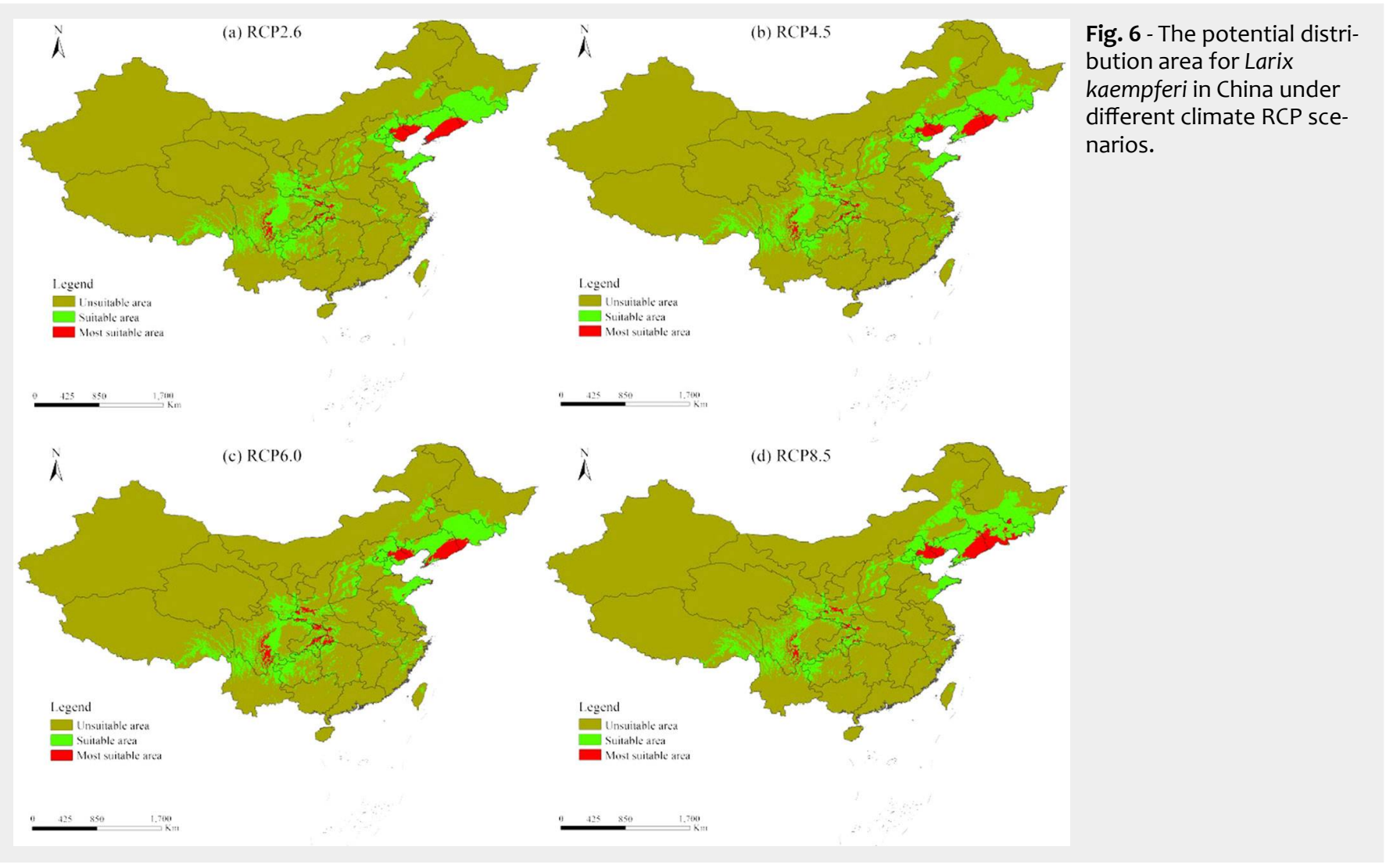


matic conditions (Saulnier et al. 2019). Asia has a temperate monsoon climate, with typical temperate continental climate characteristics (Bai et al. 2019). The average temperature of the coldest month in the north is below $0{ }^{\circ} \mathrm{C}$, and in the south is close to $20^{\circ} \mathrm{C}$ (Bai et al. 2019). The climate was characterized by cold and dry winters, and high temperatures and rain in summer (Bai et al. 2019). This was consistent with the biological characteristics of L. kaempferi, which is cold-tolerant and prefers slightly cold climate (Cáceres et al. 2017). In addition, variations in species range are becoming more common in the north with increasing latitude and altitude (Wang 2012). Climate change, human disturbances, competitive releases, and ecological characteristics of individual species may contribute to new and unexpected overlaps in species ranges, and to impediments in predicting range-bound changes in surrounding trees (Dyderski et al. 2018).

L. kaempferi may be particularly sensitive to climate change (Peng et al. 2018). A large-scale study of climatic responses of $L$. kaempferi found that the global distribution is sensitive to the several environmental conditions, such as altitude, latitude, temperature, and moisture (Nakada \& Fukatsu 2012, Alexander et al. 2018), leading to regional differences in the geographic distribution of the species (Mamet et al. 2019). In the context of global warming, forest tree species have been found to expand to higher altitudes (Tchebakova et al. 2005, Mamet et al. 2019). In the present study, the distribution of L. kaempferi in North America, Canada, Oceania Australia and New Zealand, was found to be relatively small. In the past 30 years, the average annual temperature changes in low-altitude areas have either increased or decreased by about $3{ }^{\circ} \mathrm{C}$. This suggests that temperature is a dominant factor limiting the distribution and growth of $L$. kaempferi, compared to other environmental variables. Geographical differences in the distribution-temperature response indicate that decreasing temperatures in highaltitude forests limits the distribution of $L$. kaempferi. The potential distribution areas of $L$. kaempferi in China were located mainly in Jilin, southeastern Liaoning, western Hubei and Hebei provences. This is similar to the potential distribution area obtained in previous studies (Ma 1992, Pâque 2002, Wang et al. 2008).

Direct and/or indirect effects of drought may lead to significant changes in local microclimatic conditions (Nakada \& Fukatsu 2012, Huang 2017). Due to temperature-induced drought stress, decline of tree lines and thinning of forests are becoming more frequent, thus leading to a reduction in the distribution of L. kaempferi in the south, as well as to its increase in the north (Obojes et al. 2018). Larch can tolerate harsh conditions in permafrost environments, regulate soil moisture intake under humid conditions, and benefit from the water released by the melting of ice-rich permafrost under drought conditions (Mamet et al. 2019). Therefore, the impact of environmental changes on L. kaempferi forests will ultimately depend on the balance between temperature and precipitation. Based on the native $L$. kaempferi distribution trends and current distribution-climate response patterns, we determined the distribution gradient of L. kaempferi forests along the altitudinal gradient, i.e., the distribution areas increased at high altitudes and declined at low altitudes.

Our results predict that the suitable distribution areas of L. kaempferi will respond differently to climate change in Europe, Asia and North America under the four RCP scenarios (Wang et al. 2008, Obojes et al. 2018). Of these, the potential distribution areas would increase in North America, those in Asia would decrease and shift northward, while those in Europe would fragment and shift northward, compared to the present conditions. Africa and South America did not show any potential distribution areas for L. kaempferi in the current (Tab. 2) and future climate scenarios (Tab. 3). The reason is that Larix kaempferi is limited mainly by temperature, with a survival temperature range of $2.5-12{ }^{\circ} \mathrm{C}$ (Ma 1992), while temperatures in Africa and South America are too high for the species. Although changes in temperature are expected under future climate scenarios, still the anticipated climate in the above continents will not meet the survival conditions of Larix kaempferi (Chen et al. 2016).

Our result showed that the main factors affecting the suitable distribution area of $L$. kaempferi were the annual average temperature and average annual precipitation. Extreme climates (coldest average temperature, driest monthly precipitation) were also the dominant factor affecting the distribution of L. kaempferi. Thus, extreme climate may lead to local discontinuity in species distribution (Yao et al. 2016).

\section{Conclusion}

In this study, we modeled the changes in the suitable distribution areas of L. kaempferi based on climatic factors. Most populations appear to be expanding their distribution northward. Our results can help planning the introduction and cultivation of $L$. kaempferi, thus avoiding economic losses caused by blind introduction, and increasing the yield of $L$. kaempferi. However, the predictions of this study were based only on the environmental conditions of the distribution area, being the genetic variation of the species and anthropogenic effects not considered here. Uncertainty about how these factors will change over time exist, so further studies on the patterns of L. kaempferi expansion and the underlying processes are required. Future research will include the improvement of prediction model as well as related research aimed to further characterize the future distribution of L. kaempferi, e.g., by carrying out cultiva- tion tests in suitable distribution areas, thereby confirming the area suitable for introduction and cultivation of L. kaempferi.

The spatial dynamics of $L$. kaempferi over time indicate that the global warming will contribute to the species' expansion, as it can adapt or shift to higher latitudes/altitudes. These results can aid in prioritizing geographic regions and/or larch species for further studies on their altitudinal/geographical response to climate change, in order to better understand how these deciduous gymnosperms adapt to global climate change.

\section{Acknowledgment}

We would like to thank all the researchers who made their data available for this study. This research was funded by the $\mathrm{Na}$ tional Key Research and Development Program of China (2017YFD0600401).

\section{References}

Alexander HD, Natali SM, Loranty MM, Ludwig SM, Spektor VV, Sergey D, Zimov N, Trujillo I, Mack MC (2018). Impacts of increased soil burn severity on larch forest regeneration on permafrost soils of far northeastern Siberia. Forest Ecology and Management 417: 144-153. - doi: 10.1016/j.foreco.2018.03.008

Bai XP, Zhang XL, Li JX, Duan XY, Jin YT, Chen ZJ (2019). Altitudinal disparity in growth of Dahurian larch (Larix gmelinii Rupr.) in response to recent climate change in northeast China. Science of The Total Environment 670: 466-477. - doi: 10.1016/j.scitotenv.2019.03.232

Cáceres CB, Hernández RE, Fortin Y (2017). Shrinkage variation in Japanese larch (Larix kaempferi [Lamb.] Carr.) progenies / provenances trials in Eastern Canada. Wood Material Science and Engineering 13 (2): 1-7. - doi: 10.1080/1748 0272.2017 .1327460

Chen DS, Sun XM, Zhang SG (2016). Biomass, carbon storage and nutrient characteristics in Larix kaempferi plantations at different stand ages. Chinese Journal of Applied Ecology 27 (12): 3759-3768. [In Chinese] [online] URL: http://europepmc.org/article/med/29704332 Chen FQ, Song NN, Chen GH, Wang JZ (2015). Effects of exotic species Larix kaempferi on diversity and activity of soil microorganisms in Dalaoling National Forest Park. Ecological Processes 4 (1): 612. - doi: 10.1186/s13717-015-0037-X Chen XM, Lei YC, Zhang XQ, Jia HY (2012). Effects of sample sizes on accuracy and stability of maximum entropy model in predicting species distribution. Scientia Silvae Sinicae 48 (1): 5359. [In Chinese] [online] URL: http://www.cab direct.org/cabdirect/abstract/20123266635 Dyderski MK, Paz S, Frelich LE, Jagodzinski AM (2018). How much does climate change threaten European forest tree species distributions? Global Change Biology 24: 1150-1163. - doi: 10.1111/gcb.13925

Fukatsu E, Nakada R (2018). The timing of latewood formation determines the genetic variation of wood density in Larix kaempferi. Trees 32 (5): 1233-1245. - doi: 10.1007/s0o468-018-17050

Hastie T, Tibshirani R (1990). Generalized additive models. Monographs on "Statistics and 
Applied Probability" (vol. 1), Chapman and Hall, London, UK, pp. 590-606.

Hijmans RJ, Cameron SE, Parra JL, Jones PG, Jarvis A (2005). Very high resolution interpolated climate surfaces for global land areas. In ternational Journal of Climatology 25 (15): 1965 1978. - doi: $10.1002 /$ joc. 1276

Hoshi $\mathrm{H}$ (2004). Forest tree genetic resources conservation stands of Japanese larch (Larix kaempferi (Lamb.) Carr.). Forest Tree Genetic Resources Information 1 (1): 1-4. [online] URL: http://www.ffpri-tmk.affrc.go.jp/ftbc/research/k akonokouhousi/documents/e-tokubetu.pdf Huang KF, Zhu WM, He MS (1996). Regional research on introduction of Larix kaempferi. Sichuan Forest Exploration Design 3: 21-25. [In Chinese]

Huang WW (2017). Climate responses in growth and wood anatomy of important forest tree species in Denmark. Department of Geosciences and Natural Resource Management, Fac ulty of Science, University of Copenhagen, Denmark, pp. 22. [online] URL: http://www.forsk ningsdatabasen.dk/en/catalog/2372710088

Kotani A, Saito A, Kononov AV, Petrov RE, Maximov TC, lijima $Y$, Ohta T (2019). Impact of unusually wet permafrost soil on understory veg etation and $\mathrm{CO}_{2}$ exchange in a larch forest in eastern Siberia. Agricultural and Forest Meteorology 265: 295-309. - doi: 10.1016/j.agrformet.2 018.11.025

Li GQ, Liu CC, Liu YG, Yang J, Zhang XS, Guo K (2013). Advances in theoretical issues of species distribution models. Acta Ecologica Sinica 33 (16): 4827-4835. [In Chinese] - doi: 10.5846/ stxb201212031735

Li Y, Zou D, Ren B, Ding X, Bian H, Wang J (2016). Balancing effect of larch plantations (Larix kaempferi) on understory plant diversity in a subtropical forest ecosystem, China. Applied Ecology and Environmental Research 14 (3) 397-407. - doi: 10.15666/aeer/1403_397407

Lu YH, Coops NC, Wang TL, Wang GY (2015). A process-based approach to estimate Chinese fir (Cunninghamia lanceolata) distribution and productivity in southern China under climate change. Forests 6: 360-379. - doi: 10.3390/f6020 360

Ma CG (1992). On the countermeasures for the improvement of larch in China from the status quo of genetic improvement of larch in the world. World Forestry Research 1: 57-65. [In Chinese]

Mamet SD, Brown CD, Trant AJ, Laroque CP (2019). Shifting global Larix distributions: northern expansion and southern retraction as species respond to changing climate. Journal of Biogeography 46: 30-44. - doi: 10.1111/jbi.13465

Mateo RG, Felicísimo AM, Muñoz J (2011). Species distributions models: a synthetic revision. Revista Chilena de Historia Natural 84 (2): 217240. - doi: 10.4067/S0716-078X2011000200008

Nagaike T, Hayashi A, Abe M, Arai N (2003). Differences in plant species diversity in Larix kaempferi plantations of different ages in central Japan. Forest Ecology and Management 183 (1-3): 177-193. - doi: 10.1016/S0378-1127(03)o 0105-1

Nakada R, Fukatsu E (2012). Seasonal variation of heartwood formation in Larix kaempferi. Tree
Physiology 32 (12): 1497-1508. - doi: 10.1093/tree phys/tps108

Obojes N, Meurer A, Newesely C, Tasser E, Oberhuber W, Mayr S, Tappeiner U (2018). Water stress limits transpiration and growth of European larch up to the lower subalpine belt in an inner-alpine dry valley. New Phytologist 220 (2): 460-475. - doi: 10.1111/nph.15348

Padalia H, Srivastava V, Kushwaha SPS (2014). Modeling potential invasion range of alien invasive species, Hyptis suaveolens (L.) Poit. in India: comparison of MaxEnt and GARP. Ecological Informatics 22: 36-43. - doi: 10.1016/j.ecoinf. 2014.04.002

Pâque LE (2002). Improvement of larch (Larix sp.) for better growth, stem form and wood quality. In: Proceedings of the Meeting "LARIX2002" (Pâque LE ed). Gap (France) 16-21 Sept 2002. INRA, Orleans, France, pp. 19-21.

Peng K, Peng J, Huo J, Yang L (2018). Assessing the adaptability of alien (Larix kaempferi) and native (Pinus armandii) tree species at the Baiyunshan Mountain, central China. Ecological Indicators 95: 108-116. - doi: 10.1016/j.ecolind.2018. 07.023

Phillips SJ, Anderson RP, Schapire RE (2006). Maximum entropy modeling of species geographic distribution. Ecological Modelling 190: 231-259. - doi: 10.1016/j.ecolmodel.2005.03.026 Rehfeldt GE, Jaquish BC (2010). Ecological impacts and management strategies for western larch in the face of climate-change. Mitigation and Adaptation Strategies for Global Change 15: 283-306. - doi: 10.1007/s11027-010-9217-2

Romo H, Sanabria P, Garcíabarros E (2013). Predicting climate change impacts on Lepidoptera species distribution. The case of genus Boloria Moore, 1900 in the Iberian Peninsula (Lepidoptera: Nymphalidae). Shilap-Revista de Lepidopterologia 41 (162): 267-286.

Saulnier M, Corona C, Stoffel M, Guibal F, Edouard JL (2019). Climate-growth relationships in a Larix decidua Mill. network in the French Alps. Science of the Total Environment 664: 554-566. - doi: 10.1016/j.scitotenv.2019.01.404 Shao XW (1985). Study on the ecological survey of Larix kaempferi. Journal of Shandong Forestry Science and Technology 1: 9-18. [in Chinese]

Stocker TF, Qin D, Plattner GK, Tignor M, Allen SK, Boschung J, Nauels A, Xia Y, Bex V, Midgley PM (2013). Climate Change 2013: the physical science basis. Contribution of Working Group I to the Fifth Assessment Report of the Intergovernmental Panel on Climate Change. Computational Geometry 18 (2): 95-123.

Swets JA (1988). Measuring the accuracy of diagnostic systems. Science 240 (4857): 12851293. - doi: $10.1126 /$ science. 3287615

Tchebakova NM, Rehfeldt GE, Parfenova EI (2005). Impacts of climate change on the distribution of Larix spp. and Pinus sylvestris and their climatypes in Siberia. Mitigation and Adaptation Strategies for Global Change 11: 861-882.

Wang JZ, Ding ZF, Zeng FS (2008). The breeding of Larix kaempferi. Liaoning University Press, Shenyang, Liaoning, pp. 24-26. [in Chinese]

Wang T (2012). Projecting future distributions of ecosystem climate niches in British Columbia.
Journal of Ecosystems and Management 13 (2): 1-3. [online] URL: http://jem-online.org/forrex/ index.php/jem/article/viewFile/551/476

Wang TL, Wang GY, Innes J, Nitschke C, Kang HJ (2016). Climatic niche models and their consensus projections for future climates for four major forest tree species in the Asia-Pacific region. Forest Ecology and Management 360: 357-366. - doi: 10.1016/j.foreco.2015.08.004

Wiley EO, Mcnyset KM, Peterson AT, Robins CR, Stewart AM (2003). Niche modeling and geographic range predictions in the marine environment using a machine-learning algorithm. Oceanography 16 (3): 120-127. - doi: 10.5670/oc eanog.2003.42

Williams GM, Nelson AS (2018). Spatial variation in specific leaf area and horizontal distribution of leaf area in juvenile western larch (Larix occidentalis Nutt.). Trees - Structure and Functions 32: 1621-1631. - doi: 10.1007/s00468-018-1738-4 Wu XY, Dong SK, Liu SL, Su XK, Han YH, Shi JB, Zhang Y, Zhao ZZ, Sha W, Zhang X, Gao F, Xu $\mathrm{DH}$ (2017). Predicting the shift of threatened ungulates' habitats with climate change in Altun Mountain National Nature Reserve of the Northwestern Qinghai-Tibetan Plateau. Climatic Change 142 (3-4): 331-344. - doi: 10.1007/s10584017-1939-7

Yao LI, Zhang XW, Fang YM (2016). Responses of the distribution pattern of Quercus chenii to climate change following the Last Glacial Maximum. Chinese Journal of Plant Ecology 40 (11): 1164-1178. [in Chinese] - doi: 10.17521/cjpe.2016. 0032

Yoshida T, Hasegawa M, Taira H, Noguchi M (2005). Stand structure and composition of a 60-year-old larch (Larix kaempferi) plantation with retained hardwoods. Journal of Forest Research 10: 351-358. - doi: 10.1007/s10310-005-015 4-y

Zhang L, Liu S, Sun P, Wang T, Wang GY, Zhang XD, Wang LL (2015). Consensus forecasting of species distributions: the effects of niche model performance and niche properties. PLoS One 10 (3): e0120056. - doi: 10.1371/journal.pone.012 0056

Zhang XQ, Wang Z, Chhin S, Wang HC, Duan AG, Zhang JG (2020). Relative contributions of competition, stand structure, age, and climate factors to tree mortality of Chinese fir plantations: Long-term spacing trials in southern China. Forest Ecology and Management 465: 118-103. doi: 10.1016/j.foreco.2020.118103

\section{Supplementary Material}

Appendix 1 - About the MaxEnt model.

Fig. S1 - The results of Jackknife test measuring the importance of environmental variables affecting the distribution of Larix kaempferi.

Tab. S1 - The contribution rate and replacement important values of environmental variables to affect the distribution pattern of Larix kaempferi.

Link:Wu_3570@supplo01.pdf 